\title{
Issues and Challenges of Online Job Search in India
}

\author{
Pankaj Tiwari \\ Assistant Professor, Department of CSE, \\ S.I.E.T., AKTU \\ Nisha Yadav \\ Department of CSE \\ S.I.E.T., AKTU
}

Priya Gupta

Department of CSE

S.I.E.T., AKTU

\begin{abstract}
The importance of job search systems is increasing day by day. But the applicants are facing so many problems. In today's scenario, most of the jobs which we find on the job portals are fake. When the job seeker reach the destination of the industry, the conditions arises like whether the company does not exist or the company is not up to the mark according to the acceptance of the user. This project is an attempt to minimize the problems of an applicant to find a correct job. Our main motto is to provide $100 \%$ correct job search. Far from upsetting matters, however, new technologies have predominantly made life better and considerably easier for most people, and so it must be concluded that they should be welcomed. If we can make it an online computerized and a mobile alert process, it will be so fast and convenient for the applicants.

Software does not require a dedicated computer and can be run on almost any PC running Windows OS The package includes the online job portal software and a normal cell phone and Internet connection.
\end{abstract}

\section{General Terms}

Your general terms must be any term which can be used for general classification of the submitted material such as Pattern Recognition, Security, Algorithms et. al.

\section{Keywords}

Job portal, Recruiter, job seeker, consultancy, FMGC, BPO, BFSI, Job Boards, Genuine, Infrastructure.

\section{INTRODUCTION}

Portals have different applications or services to solve various job related problems. One of the main purposes of web portals is to allow information sharing over the Internet. For example, in a university, the new students in the collage need access to information resources to select courses and to decide on the different majors available, in the curriculum. This need can be addressed through a knowledge portal which must contain and sufficient data and information about the requirements of the students. Similarly, the number of jobless graduates has become one of the serious problems existing both in the developing and developed countries, today. A job portal is a kind of web portal that provides an efficient ways for searching on the Internet or the web for vacant job positions available. This research will look at various types of web portals but will, in particular look, at job portals as a knowledge management system based on a standard framework which will provide the correct and accurate result for any kind of job search. This project will focus on the information about different types of jobs available, as needed by job seekers and also the complete details about both the job seekers profile and the industry background. Web Portals have become more important than ever because of the need to get access to find information and to acquire Knowledge, through the Internet. Existing web portals are studied to come out with the conceptual framework for the web portal to be developed in this project. The problems to address in this project would be on how to improve services to the job seekers as well as recruiters by using the internet.

\section{LIST OF THE TRADITIONAL (OLD) WAYS FOR RECRUITMENT}

1) Employment recruitment agencies

2) Job fairs

3) Advertising in the mass media such as newspapers

4) Advertisement in television and radio

5) Management Consultants

6) Existing employee contacts

7) Schools colleges or universities students services department

8) Workers or professional referrals

These old job seeking methods are too slow, stressful, challenging and also lack quality. In addition, the applicants have to consider the cost and the amount of time to get the information they need, and other preparations they have to make. Finding all available job vacancies is a main step at in the job-seeking process. The Internet is now a powerful tool that jobseekers can use. Today, there are many sites that advertise job positions to be filled by people with certain skills in various fields. 


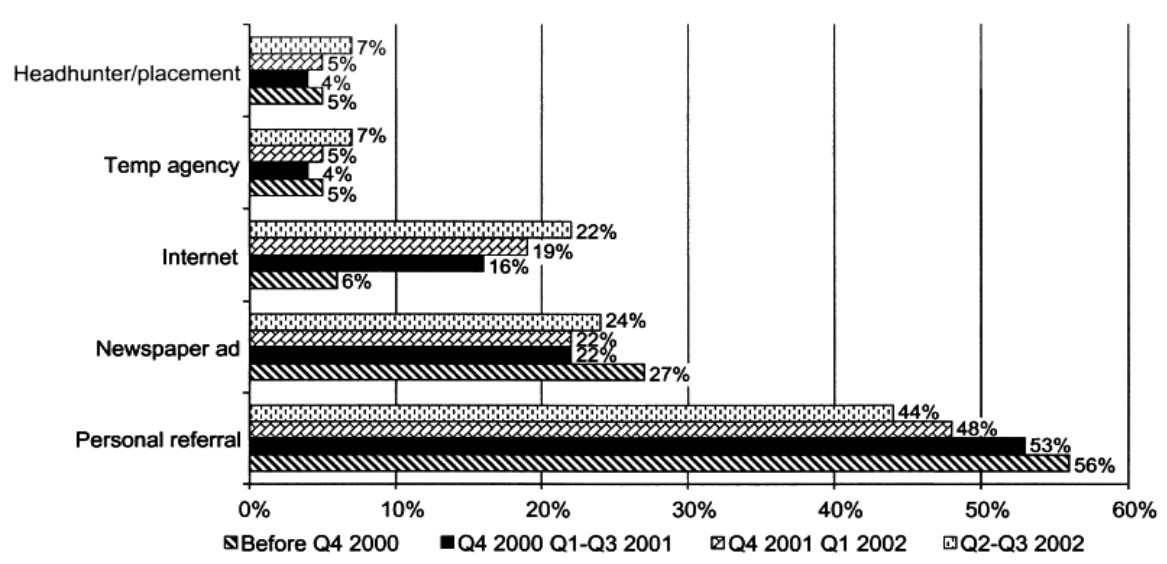

Fig 1: Graphical representation of the various traditional methods of recruitment

The Internet plays an important role in the area of human resource planning and development. Most planning and development organizations are now using computer technology and the Internet for staff recruitment. It should be noted that although the Internet has facilitated the process of job-seeking, it has not replaced the traditional methods, completely. Even now most of the population is still depending on the news papers and the ads to find the job.

\section{PROBLEMS OF ONLINE JOB \\ PORTALS FACED BY JOB SEEKERS}

In today's scenario, the one who is in requirement of job, go through the famous job portals of today. But they came across some problems which make online job portal systems lacking somewhere. Some of the issues which are faced by the job seekers while finding job through online portals are-

1) Many of the jobs are not real i.e., they are fake which are listed in the portals.

2) The companies listed do not give their actual structure and environment where the industry is located.

3) The portals do not take responsibility of the jobs listed on the portals whether they are genuine or not.

4) Users have to travel to the place where industry is located several times before the final recruitment which waste their time and money.

5) Also, some of the job portals ask for the money before the commencement of the job.

To overcome all these above listed problems, our website will be checking the validity of the company by itself and then we will display the result which will be totally real and well observed by our team members.

\subsection{Discussion on the Above Problems}

1) The jobs listed in the job portal are not real. Many jobs the companies post on the job portals are fake. They do not account for the same post or for the same salary as they have mentioned on the job portal. Even the location or the environment in which the industry in situated is not mentioned correct. So, many users are not satisfied with this kind of miss happenings.

2) The companies do not even represent their real structure on the portals. They give fake structures of their industries on the job portals. Even the companies are working in one room; they mention it like 5 stories building. All this cannot gather many users. This is one point where job portals are lagging. 3) Also, job portals of today's scenario do not take the responsibility of the jobs which are being posted on the portals. They have nothing to do with the reality of the jobs. They allow all types of the jobs to be posted on the portals. They do not check whether the jobs are according to the requirement of the job seeker or not.

4) The users who use the job portals are totally dependent on the time and the place of the test and the interview. They have to move again and again for the sake of recruitment and finally if they do not get placed, they have to bear the loss of both money

5) When the users upload their resume on any of the job portals, they ask for the money as registration to fill the form and give the test for the job. All this leads to the loss of money and time before the commencement of the job. User has to pay that money then only he or she can be able to.

So, all these factors affect the no. of users using the job portals.

\section{PROBLEMS FACED BY RECRUITERS}

While recruiting, the recruiters have to be very careful about the validity of the person who has applied for the job online. The company also needs a good worker for their industry. For their, they have to check the validity of the users profile and qualifications.

The various problems faced by the recruiters are:

1) Many of the users post their fake qualifications on the portals.

2) Also they post the skills in which they are not completely perfect. Due to this, the portal members have to waste their time in connecting to them for the jobs which match their profile.

3) Overflow of applicants.

4) Too many tests, too many cheaters.

\section{RECRUITMENT TREND IN INDUSTRY IN 2017}

Skills demand increased by 4 per cent in May 2017 with Business Process Outsourcing (BPO) and Banking Financial services and Insurance (BFSI) sectors showing an increase of 24 and 14 per cent in the talent demand, respectively. During 
the month of April 2017, hiring registered an increase of 3 percent.

Automobiles and consulting services sectors also posted considerable rise in talent demand during the month. Healthcare sector posted 15 per cent rise in demand. Consulting services sector reported a rise of 13 per cent in talent demand. Both automobiles and BFSI sectors saw 12 per cent rise in demand. Real estate sector posted 9 per cent rise in demand. Customer service professionals reported over 20 per cent rise in demand. Doctors, nurse and medical professionals witnessed 19 per cent rise in demand. Accounting and finance professionals saw 8 per cent rise in demand and IT/telecom profile witnessed 6 per cent rise.
However, senior professionals posted a 5 per cent rise in demand. Candidates with over 20 years of experience reported highest rise of over 20 percent in demand during May 2017. Professionals with 10-20 years of experience posted 14 per cent rise in talent demand, followed by candidates with 5-10 years of experience with 7 per cent rise. Candidates with 2-5 years of experience witnessed 6 per cent rise, while candidates with less than 2 years of experience reported 3 per cent rise. Talent demand grew significantly in tier II locations and there was positive hiring momentum in most major locations during May 2017. Jaipur was the best performing location during the month.

\section{Demand for talent}

May $17 \quad$ Apr 17

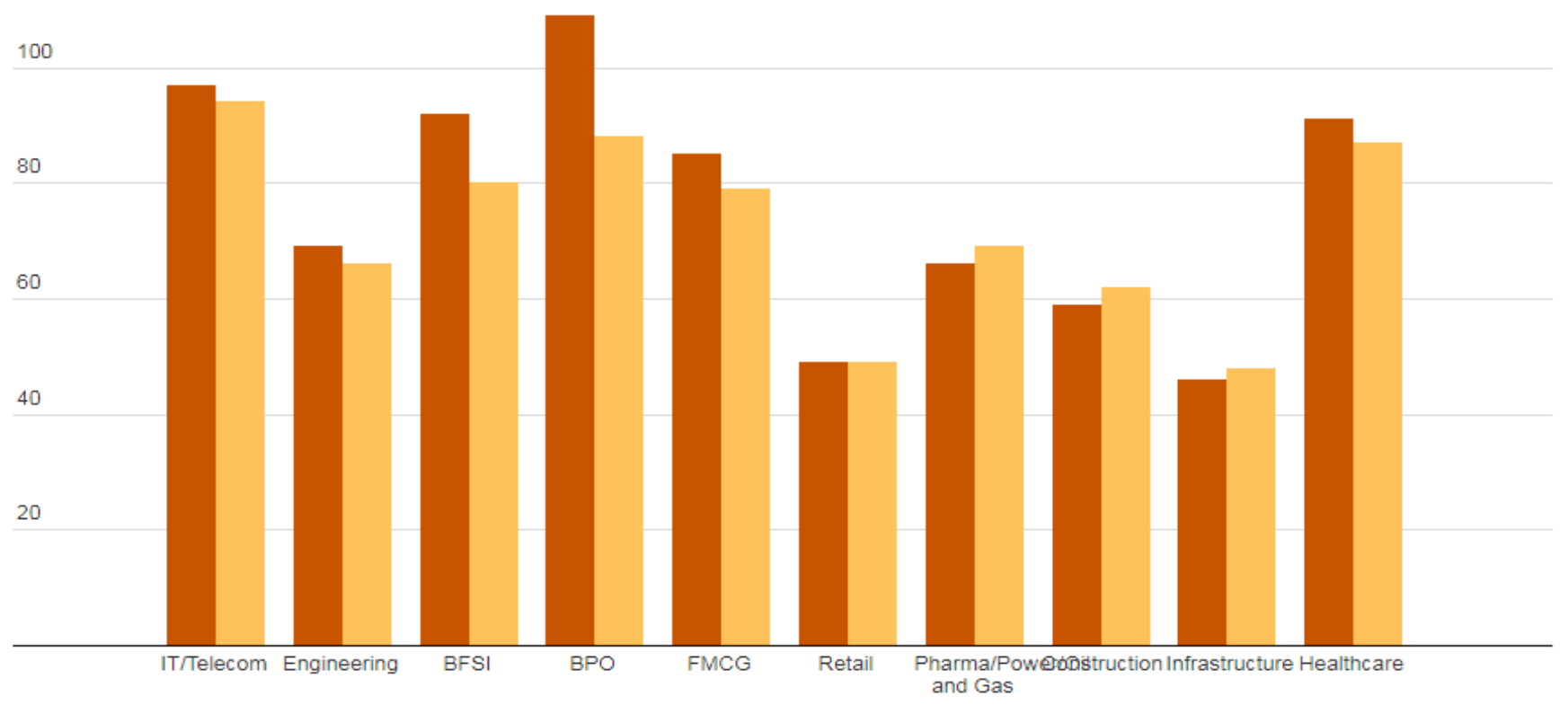

Fig 2: Recruitment trend in industry in 2017

\section{PROCESSING DIAGRAM OF BOTH OFFLINE AND ONLINE RECRUITMENT SYSTEM $^{[5]}$}
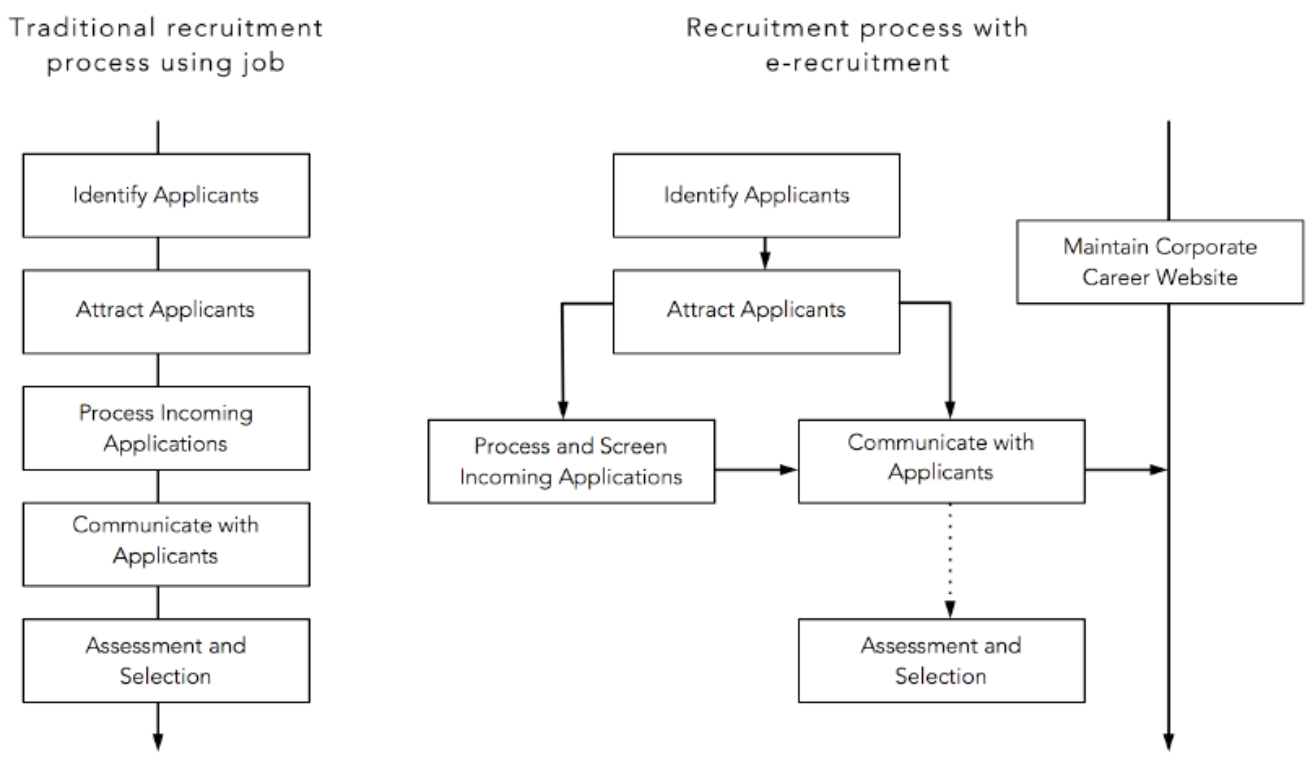
Fig 3: The design and sequence of the tasks in paper-based recruitment and online recruitment system.

\section{SURVEY DONE TO SEE WHICH IS BETTER- ONLINE OR OFFLINE METHOD OF RECRUITMENT.}

The comparison between those who have applied for a job through traditional means (finding a job through newspapers, employment offices, temporary agencies, help-wanted posters) and those who have applied for a job through a social media network then applying through an electronic channel differ greatly. Figure lists the responses for the two questions regarding applying for a job through traditional and online channels. $80 \%$ of the participants have found a job through traditional means whereas only $32 \%$ of the participants have applied through an online channel. It was intriguing to see that
26 respondents said they have applied for a job using both traditional and online channels. In the figure, it is illustrated under "Both". The author pondered about the responses that said no to both, this totaled to 11 out of the 83 respondents. After exploring to see if the reasoning behind this was due to never having a job, however, the author did not find a correlation. Each respondent that answered no to both questions said they were either currently employed or have had a job within the last three years. The next reasoning that could be behind these responses is that they have never had to apply for their work; perhaps working at a family business or was passively recruited for their role. There is also a possibility that the respondents misunderstood each question.

\section{Have you ever applied for a job that you found through...}

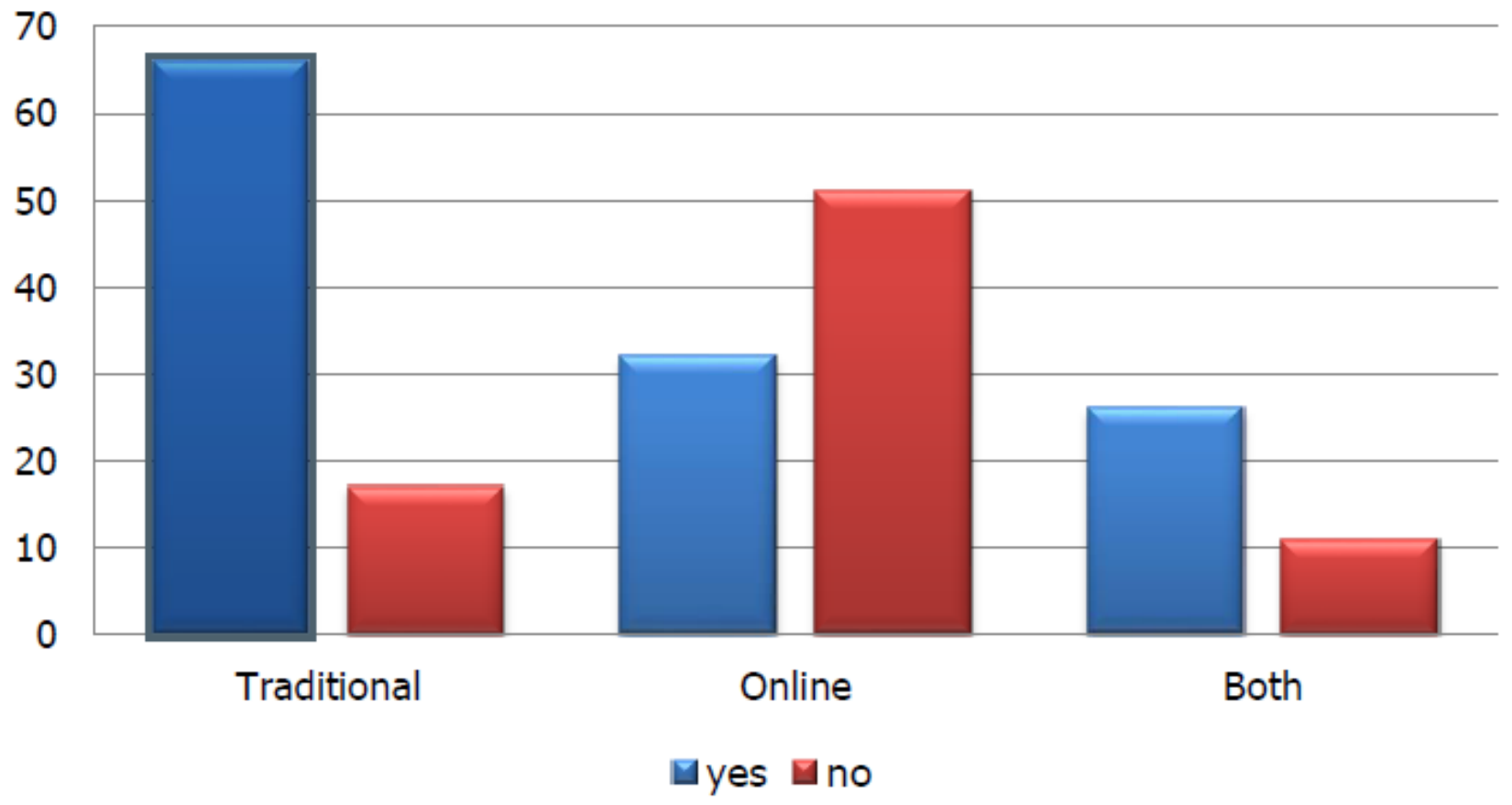

Fig 4: The design and sequence of the tasks in paper-based recruitment and online recruitment system

\section{WHAT'S NEW- PROPOSED MODEL}

This project can act as a solution for all the problems listed above. Our website will act as an intermediate between the job seekers and the recruiters. Our team will check for both the recruiters and the job seekers whether they are real or not. We will provide the various pages for both the company and the job seekers on the website in order to check their validity. We will provide the facility to the job seekers by providing the actual infrastructure of the industry on the website. This will be done by checking the location and environment of the industry. And similarly, our team will check job seekers also whether the resume uploaded by them is according to their qualifications or not. Or they have given the wrong information about their qualifications or related to age. To check this, our team will do the screening of the documents manually and the result will be shown in the users account. This will help the recruiters to indentify the valid user.
Keeping in mind the above problems which are faced by job seekers and the recruiters, we have proposed some new features which should be added to the website of online job portal. As we can see in the block diagram, the Admin is the controlling mind of whole website. The admin will verify both the job seeker and the company. Our website is divided into two modules i.e., one is the normal online recruitment process and the other is admin controlling actions via Career booster team members. Job seeker will register to the website and the notification is send to the admin panel. He will upload the resume. The admin will then verify the uploaded resume by screening process. The screening of the resume will be done manually by the team members. If the resume is up to the mark then the admin will send the feedback to the jobseeker for the sake of the verifiability. Similarly, in the case of recruiting company, they will also register to the concern website and the notification will be send to the admin panel and the admin has to verify the company that is registered. The admin will verify the company environment, its salary 
package, will take the feedback of the workers working in the company and also the infrastructure of the company through the career booster team. After the admin is satisfied will the profile of the company, then only the company is allowed to post their concern job vacancies on the website. In this way, we are in a hope to provide the best for both the jobseekers and the recruiters.

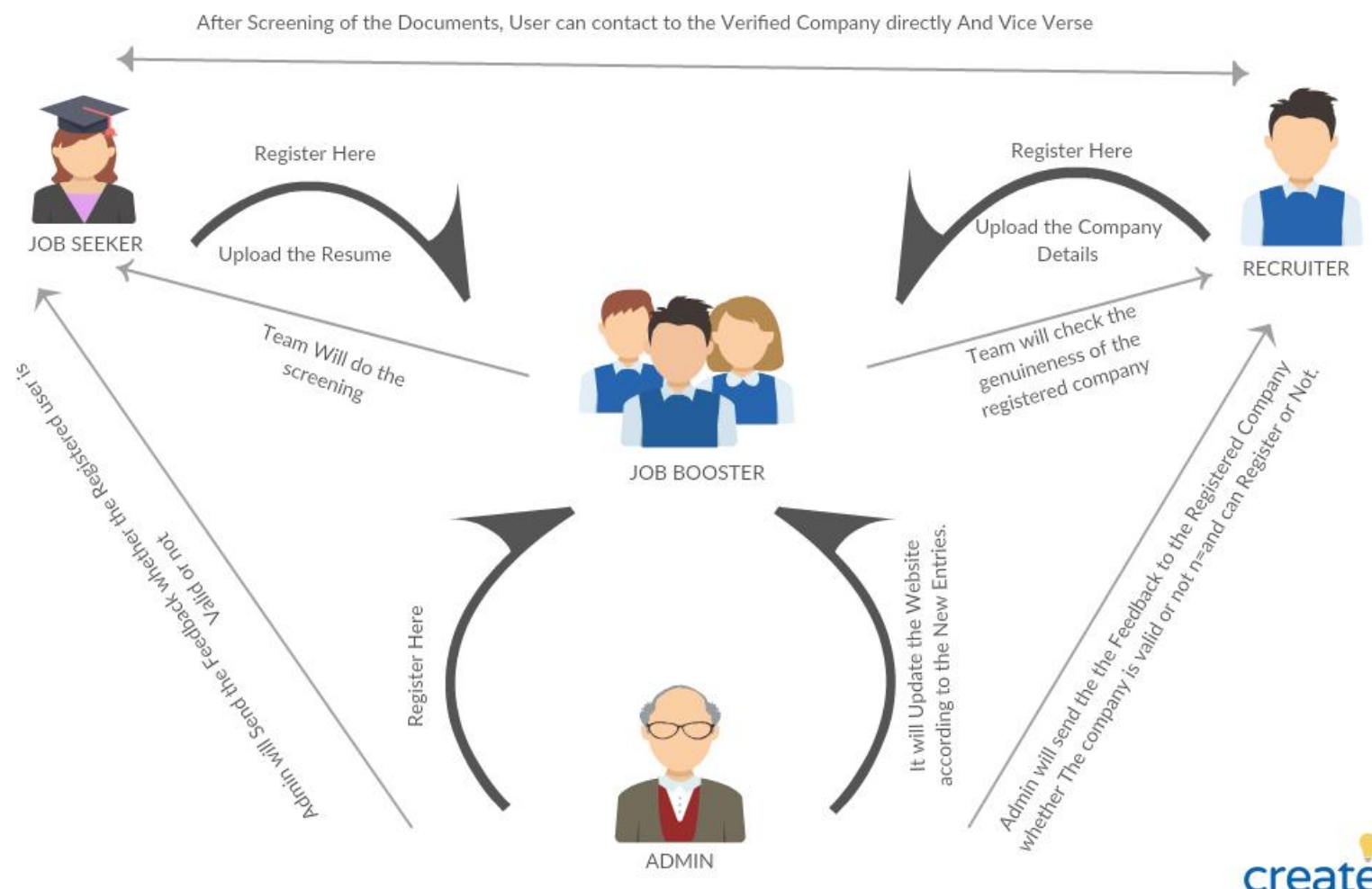

creately

Fig 5: Block Diagram representing the working of our project.

\section{CONCLUSION}

This paper provides an exploratory study of the recruitment process. The purpose was to investigate how the recruitment process has evolved from the traditional paper-based process to the modern day recruitment process. The author concentrated on two point-of-views: recruiters and job seekers. The objective was to find how each side perceived the current trends and the effect on job search today. Our website can be a solution for the problems listed above. Our website will check whether the jobs posted on the website are genuine or not. Our website will also check whether the infrastructure of the industry is same as mentioned on the website. Also, our website will also help the industries to check whether the job seekers are genuine or not. The qualifications they have entered are correct or not? The resume they entered is genuine or not. So, our team will act as an intermediate between the job seeker and the industry i.e., recruiter by providing the best result for the online job search. We will try to give $100 \%$ job guarantee to the users and the valuable and compatible worker to the organization. The developers challenged various issues to develop a system for responding some problems that job seekers and companies are facing today. The main aim of this work is to develop a web portal, which caters for various types of users and is easy to use. This work had focused on improving the online job portals.

\section{ACKNOWLEDGEMENT}

Our heartily thanks to the project guide Mr. Pankaj Tiwari, Assistant Professor, Dean Member of Department of CSE S.I.E.T AKTU (Allahabad) for the contribution and the guidance given by him in completing the survey and research.

\section{REFERENCES}

[1] http://www.ijcte.org/papers/834-Z048.pdf

[2] https://diuf.unifr.ch/main/is/sites/diuf.unifr.ch.main.is/fil es/documents/student-projects/S2014_Celine_Deillon_0.pdf

[3] https://careerdirectionsllc.com/prescriptions-for-toughjob-search-problems/

[4] https://www.google.co.in/search?q=survey+supported+b $\mathrm{y}+$ graphs+on+issues+and+challenges+of+online+job+se 


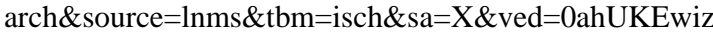
n6OplKPaAhVLvY8KHT9XC-

UQ_AUICygC\&biw $=1366 \&$ bih $=613 \#$ imgrc $=$ QNOAK68 L29y1LM

[5] https://diuf.unifr.ch/main/is/sites/diuf.unifr.ch.main.is/fil es/documents/student-projects/S2014_Celine_Deillon_0.pdf

[6] http://ieeexplore.ieee.org/document/6959916/

[7] http://gnu.inflibnet.ac.in/bitstream/123456789/2226/1/On line \%20Job\%20Portal.pdf

[8] http://www.nber.org/papers/w13886

[9] https://blog.rpoassociation.org/blog/5-top-challenges-oftalented-job-seekers

[10] https://www.quora.com/What-are-the-biggestchallenges-facing-online-recruitment-What-are-the-keyinefficiencies-and-challenges-both-for-candidates-aswell-as-companies-hiring

[11] https://www.vpi-inc.com/2016/07/27/top-threechallenges-facing-first-time-job-seekers/

[12] https://diuf.unifr.ch/main/is/sites/diuf.unifr.ch.main.is/fil es/documents/student-projects/S-

2014_Celine_Deillon_0.pdf
[13] https://careerdirectionsllc.com/prescriptions-for-toughjob-search-problems/

[14] https://www.linkedin.com/pulse/challenges-freshgraduate-job-searching-akshat-jha

[15] https://www.businessnewsdaily.com/5732-online-jobapplication-problems.html

[16] http://www.employment-studies.co.uk/reportsummaries/report-summary-e-recruitment-it-delivering

[17] https://www.jibe.com/wp-content/uploads/2014/09/2014Talent-Acquisition-Survey.pdf

[18] https://www.theseus.fi/bitstream/handle/10024/80428/Sil 1s_Maureen.pdf?sequence $=1 \&$ isAllowed $=y$

[19] https://www.robertwalters.com/content/dam/robertwalters/corporate/news-and-pr/files/whitepapers/usingsocial-media-in-the-recruitment-process.pdf

[20] https://www.google.co.in/search?q=survey+supported+b $\mathrm{y}+$ graphs+on+issues+and+challenges+of+online+job+se arch \&source $=$ lnms\&tbm $=$ isch $\&$ sa $=X \& v e d=0$ ahUKEwiz n6OplKPaAhVLvY8KHT9XC-

UQ_AUICygC\&biw=1366\&bih=613\#imgrc $=$ QNOAK68 L29y1LM: 